\title{
Radial Microstrip Slotline Feed Network for Circular Mobile Communications Array
}

Rainee N. Simons

Sverdrup Technology, Inc.

Lewis Research Center Group

Brook Park, Ohio

Eron S. Kelly

Princeton University

Princeton, New Jersey

and

Richard Q. Lee and Susan R. Taub

National Aeronautics and Space Administration

Lewis Research Center

Cleveland, Ohio

Prepared for the

1994 IEEE AP-S International Symposium and URSI Radio Science Meeting sponsored by the Institute of Electrical and Electronics Engineers

Seattle, Washington, June 19-24, 1994

Aational Aeronautics and

Space Administration 


\title{
RADIAL MICROSTRIP SLOTLINE FEED NETWORK FOR CIRCULAR MOBILE COMMUNICATIONS ARRAY
}

\author{
Rainee N. Simons*, Eron S. Kelly, Richard Q. Lee and Susan R. Taub \\ NASA Lewis Research Center, Mail Stop 54-5 \\ 21000 Brookpark Road, Cleveland, Ohio 44135
}

\begin{abstract}
INTRODUCTION
In mobile and satellite communications there is a need for low cost and low profile antennas which have a toroidal pattern. Antennas that have been developed for mobile communications include a L-Band electronically steered stripline phased array, a Ka-Band mechanically steered elliptical reflector antenna and a Ka-Band printed dipole [1]. In addition, a L-Band mechanically steered microstrip array [2], a L-Band microstrip phased array tracking antenna for mounting on a car roof [3] and a X-Band radial line slotted waveguide antenna [4] have been demonstrated. In the above electronically scanned printed arrays [1] and [3], the individual element radiates normally to the plane of the array and hence require a phase shifter to scan the beam towards the horizon. Scanning in the azimuth is by mechanical or electronic steering. An alternate approach [5] is to mount microstrip patch radiators on the surface of a cone to achieve the required elevation angle. The array then scans in the azimuth by beam switching.
\end{abstract}

In this paper a planar circular array with endfire linearly tapered slot antenna (LTSA) elements [6] is described. The LTSA has several advantages which include high element gain, wide bandwidth, equal beam width in the two orthogonal planes by proper choice of flare angle and simple construction. The circular array radiates in the radial direction in the azimuth plane and hence eliminates the need for phase shifters and mechanical scanning hardware. To achieve the elevation angle a ground plane is placed below the array which causes the beam to tilt above the horizon. The ground plane also simulates the metal roof top of vehicles. The feed network consists of a sixteen way radial power splitter which is electromagnetically coupled to the LTSA circular array. Electromagnetic coupling eliminates pin and solder connections and therefore improves reliability and lowers the cost. It also results in a wider bandwidth. This type of feed network is very simple and therefore has potential applications in several other configurations of planar microstrip patch arrays also.

\section{FEED NETWORK AND ARRAY DESIGN}

The feed network and the LTSA array shown in Fig.1 are designed for operation at a center frequency $f_{0}$ of $18 \mathrm{GHz}$. The microwave power is surface launch by a modified OS-50 coaxial connector to the input of the power splitter. The microstrip line through a series of tee junctions and right angle bends divides into sixteen radial output ports. The characteristic impedance $Z_{0 m}$ of the 
microstrip line is maintained as $50 \Omega$ throughout the splitter. In the tee junction compensation of discontinuity reactances is done by removing a portion of the line in the shape of an isosceles triangle with angle $\theta=45^{\circ}$ [7]. The measured excess insertion loss and return loss of the tee junction is $0.3 \mathrm{~dB}$ and $11 \mathrm{~dB}$ respectively at $f_{0}$. The transition consists of a microstrip line and a slotline which are orthogonal to each other and on opposite sides of a substrate (see inset in Fig.2). Further, the microstrip line is terminated at a distance of $\mathrm{L}_{m}$ in an open circuit and the slotline is terminated at a distance of $L_{s}$ in a short circuit from the junction. The slotline width $W_{S}$ is chosen from ease of fabrication as $0.127 \mathrm{~mm}$ and the characteristic impedance $Z_{O s}$ is $112 \Omega$ [8]. To provide good impedance match $Z_{O m}$ has to be less than $Z_{O S}$ by 10 to 20 ohms [9]. Hence $Z_{O m}$ of $100 \Omega$ is chosen for the microstrip line. The corresponding $W_{m}$ is $0.21 \mathrm{~mm}$. The lengths $L_{s}$ and $L_{m}$ after correcting for discontinuity end effects are 0.207 and 0.214 times the respective guide wavelength at $f_{0}$. The performance of the transition is evaluated both with and without a right angle bend (see inset in Fig. 2). The right angle bend is compensated by chamfering the corner such that the distance from the inner corner to the opposite edge is 0.828 times the microstrip line width $W_{m}$ [7]. The insertion loss and return loss of two backto-back transitions with $4 \mathrm{~mm}$ of slotline in between as measured in the test fixture is shown in Fig. 2. For each half the insertion loss is about $1.1 \mathrm{~dB}$ and 1.6 $\mathrm{dB}$ without and with a right angle bend respectively at $\mathrm{f}_{0}$. The corresponding return loss is about $25 \mathrm{~dB}$ and $17 \mathrm{~dB}$ respectively. The LTSA is formed by gradually flaring the width of the slotline. The measured return loss of a single LTSA with the above transition is better than $15 \mathrm{~dB}$ at $\mathrm{f}_{0}$. The dimensions of the circular array is presented in Fig.1.

\section{FEED NETWORK AND ARRAY PERFORMANCE}

The measured H-plane pattern is shown in Fig. 3(a). Also shown is the pattern without the ground plane. In the presence of a ground plane the pattern is displaced by about $28^{\circ}$ in the elevation. The $3 \mathrm{~dB}$ beamwidth is about $22^{\circ}$. By tilting the array in the elevation, the E-plane pattern is measured and Fig. $3(\mathrm{~b})$ shows a typical peak pattern. The ripple in the pattern is less than $\pm 2 \mathrm{~dB}$. The E-plane pattern is also measured for each of the four quadrants by rotating the array sequentially by $90^{\circ}$. The four radiation patterns are found to be similar which demonstrates that the array has an omni directional characteristic in the azimuth plane. The measured return loss of the array at the coaxial port is shown in Fig. 4. The return loss is better than $10 \mathrm{~dB}(2: 1 \mathrm{VSWR})$ over the frequency range of 18 to $20 \mathrm{GHz}$. The array has a gain of about $10 \mathrm{~dB}$.

\section{CONCLUSIONS AND DISCUSSIONS}

The measured characteristics of a microstrip-to-slotline transition and its application in the feed network of a sixteen element circular LTSA array is presented. The pattern measurements show that the array has omni directional characteristics in the azimuth plane. In the elevation plane, the main beam is displaced by about $28^{\circ}$ and the $3 \mathrm{~dB}$ beam width is about $22^{\circ}$. The return loss is 
better than $10 \mathrm{~dB}$ over the frequency range of 18 to $20 \mathrm{GHz}$. The array has a gain of about $10 \mathrm{~dB}$. The height of the antenna is less than $10 \mathrm{~mm}$.

\section{REFERENCES}

[1] J.Huang, et al.,"Downsizing Antenna Technology for Mobile and Satellite Communications," IEEE Antennas and Propagation Society Inter. Symp. Digest, Vol.III, pp.1834-1837, 1993.

[2] A.W. Jongejans, et al.,"Review of ESA Mobile Antenna Developments for Satellite Communications," IEEE Antennas and Propagation Society Inter. Symp. Digest, Vol.III, pp.1838-1841,1993.

[3] K. Sato et al.,"Development and Field Experiments of Phased Array Antenna for Land Vehicle Satellite Communications," IEEE Antennas and Propagation Society Inter. Symp. Digest, Vol.II, pp.1073-1076, 1992.

[4] J.-I. Takada et al., "A Dual Beam Linearly-Polarized Radial Line S I o t Antenna," IEEE Antennas and Propagation Society Inter. Symp. Digest, Vol.III, pp.1624-1627, 1993.

[5] A. Petosa et al., "Microstrip Antenna Array for Mobile Satellite Communications," IEEE Antennas and Propagation Society Inter. Symp. Digest, Vol.I, pp.503-506, 1992.

[6] R.N. Simons and R.Q. Lee, "Nonplanar Linearly Tapered Slot Antenna with Balanced Microstrip Feed," IEEE Antennas and Propagation Society Inter. Symp. Digest, Vol.IV, pp.2109-2112, 1992.

[ 7 ] R. Chadha and K.C. Gupta, "Compensation of Discontinuities in Planar Transmission Lines," IEEE Trans. Microwave Theory Tech., Vol. MTT-30, No.12, pp.2151-2156, Dec. 1982.

[8] R. Janaswamy and D.H. Schaubert, "Characteristic Impedance of a W i de Slotline on Low-Permittivity Substrates," IEEE Trans. Microwave Theory Tech., Vol. MTT-34, No.8, pp.900-902, Aug. 1986.

[9] S.B. Cohn, "Slotline on a Dielectric Substrate," IEEE Trans. Microwave Theory Tech., Vol. MTT-17, No.12, pp.768-778, Oct. 1969. 


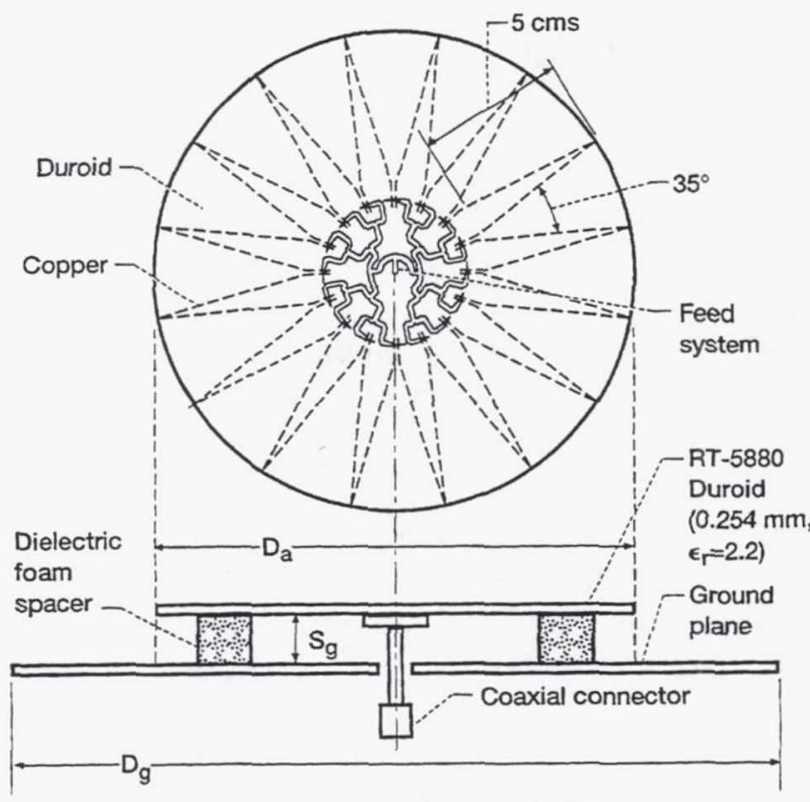

Figure 1.-Electromagnetically coupled microstrip-to-slot line feed network for a K-band circular sixteen element LTSA array. $D_{a}=16 \mathrm{cms}, D_{g}=30 \mathrm{cms} \& S_{g}=5 \mathrm{~mm}\left(0.286 \lambda_{0}\right)$.
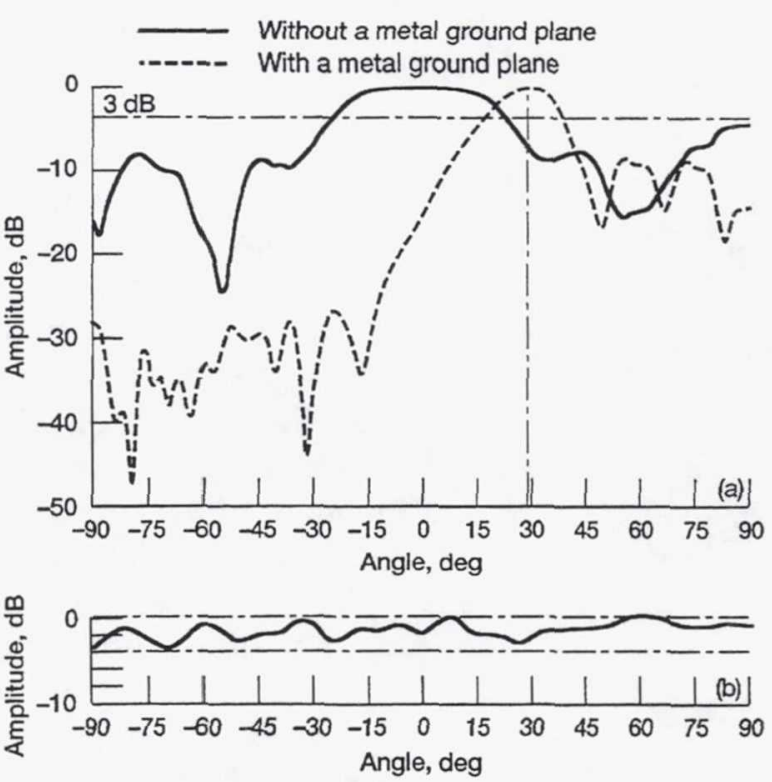

Figure 3.-Measured radiation pattern of the Array at $19 \mathrm{GHz}$. (a) H-Plane. (b) E-Plane with a metal ground plane and with the Array tilted.

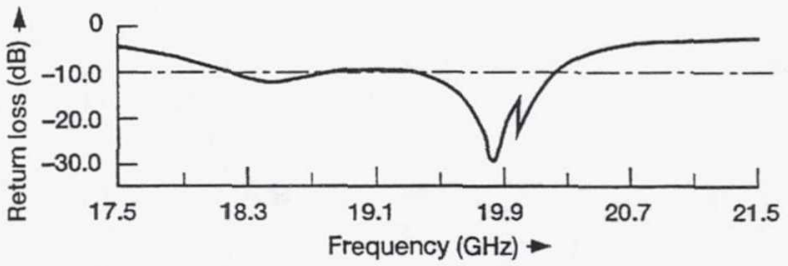

Figure 4.- Measured return loss at the coaxial port.

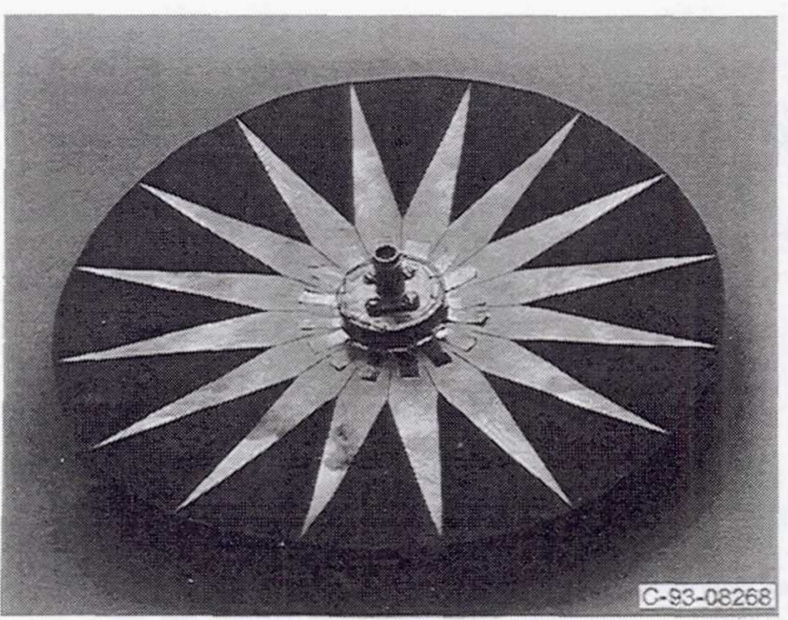

Figure 5.-Photograph of the antenna showing the coaxial feed. 
Public reporting burden for this collection of information is estimated to average 1 hour per response, including the time for reviewing instructions, searching existing data sources, gathering and maintaining the data needed, and completing and reviewing the collection of information. Send comments regarding this burden estimate or any other aspect of this collection of information, including suggestions for reducing this burden, to Washington Headquarters Services, Directorate for Information Operations and Reports, 1215 Jefferson
Davis Highway, Suite 1204, Arlington, VA 22202-4302, and to the Office of Management and Budget, Paperwork Reduction Project (0704-0188), Washington, DC 20503.

\begin{tabular}{|l|l|r|}
\hline 1. AGENCY USE ONLY (Leave blank) & $\begin{array}{r}\text { 2. REPORT DATE } \\
\text { April } 1994\end{array}$ & $\begin{array}{r}\text { 3. REPORT TYPE AND DATES COVERED } \\
\text { Technical Memorandum }\end{array}$ \\
\hline
\end{tabular}

\section{TITLE AND SUBTITLE}

Radial Microstrip Slotline Feed Network for Circular Mobile Communications Array

6. AUTHOR(S)

Rainee N. Simons, Eron S. Kelly, Richard Q. Lee and Susan R. Taub
5. FUNDING NUMBERS

WU-506-44-2C

\section{PERFORMING ORGANIZATION NAME(S) AND ADDRESS(ES)}

National Aeronautics and Space Administration

Lewis Research Center

Cleveland, Ohio 44135-3191
8. PERFORMING ORGANIZATION REPORT NUMBER

E-8683

10. SPONSORING/MONITORING AGENCY REPORT NUMBER

NASA TM-106540

National Aeronautics and Space Administration

Washington, D.C. 20546-0001

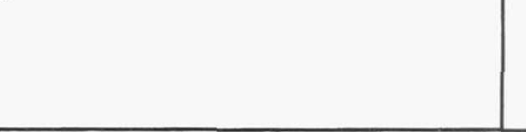

11. SUPPLEMENTARY NOTES

Prepared for the 1994 IEEE AP-S International Symposium and URSI Radio Science Meeting sponsored by the Institute of Electrical and Electronics Engineers, Seattle, Washington, June 19-24, 1994. Rainee N. Simons, Sverdrup Technology, Inc., Lewis Research Center Group, (work funded by NASA Contract NAS325266), presently at NYMA, Inc., Engineering Services Division, 2001 Aerospace Parkway, Brook Park, Ohio 44142; Eron S. Kelly, Princeton University, Princeton, New Jersey 08540, Department of Electrical Engineering and Summer Intern at NASA Lewis Research Center and Richard Q. Lee and Susan R. Taub, NASA Lewis Research Center. Responsible person, Richard W. Lee, organization code 5640, (216) 433-3489.

12a. DISTRIBUTION/AVAILABILITY STATEMENT

Unclassified - Unlimited

Subject Category 33

\section{ABSTRACT (Maximum 200 words)}

In mobile and satellite communications there is a need for low cost and low profile antennas which have a toroidal pattern. Antennas that have been developed for mobile communications include a L-Band electronically steered stripline phased array, a Ka-Band mechanically steered elliptical reflector antenna and a Ka-Band printed dipole [1]. In addition, a L-Band mechanically steered microstrip array [2], a L-Band microstrip phased array tracking antenna for mounting on a car roof [3] and an X-Band radial line slotted waveguide antenna [4] have been demonstrated. In the above electronically scanned printed arrays [1] and [3], the individual element radiates normally to the plane of the array and hence require a phase shifter to scan the beam towards the horizon. Scanning in the azimuth is by mechanical or electronic steering. An alternate approach [5] is to mount microstrip patch radiators on the surface of a cone to achieve the required elevation angle. The array then scans in the azimuth by beam switching.

\begin{tabular}{|c|c|c|}
\hline \multicolumn{3}{|c|}{$\begin{array}{l}\text { 14. SUBJECT TERMS } \\
\text { Microstrin. Slotline: Mobile communications. Circular array }\end{array}$} \\
\hline $\begin{array}{l}\text { 17. SECURITY CLASSIFICATION } \\
\text { OF REPORT } \\
\text { Unclassified }\end{array}$ & $\begin{array}{l}\text { 18. SECURITY CLASSIFICATION } \\
\text { OF THIS PAGE } \\
\text { Unclassified }\end{array}$ & $\begin{array}{l}\text { 19. SECURITY CLASSIFICATION } \\
\text { OF ABSTRACT } \\
\text { Unclassified }\end{array}$ \\
\hline
\end{tabular}

